\title{
The treatment of land use, land use change and forestry in the post-2012 climate agreement: a perspective from non-Annex I Parties
}

\begin{abstract}
Federici S, Galluzzi G
Given the greater vulnerability of developing countries to climate change, their paramount interest is to establish effective mitigation policies including the land use and forestry sectors as part of the post-2012 Climate Agreement. In this context, an accounting system for land use, land use change and forestry acceptable to non-Annex I Parties can arise only if critical elements in current accounting rules are removed and a solution to data uncertainties is found. Indeed, current accounting rules oppose the fundamental principles outlined in the both Convention on climate change and in the Kyoto protocol. They require accounting of only a portion of land-use activities and exclude forest management, give special provisions to exclude some net emissions from accounting, do not require the use of a reference level in quantifying net emissions and risk remunerating business as usual mitigation actions. Encouragingly, the current negotiation text contains options which, if adopted, would define an accounting system capable of responding to developing countries' expectations. These options include the establishment of a national reference level suited to country-specific circumstances and other measures to ensure that only truly additional mitigation actions are remunerated and that all anthropogenic net emissions on managed lands are included. Finally, the opportunity of applying the principle of conservativeness in the future accounting routine is discussed, as a straightforward and effective instrument to correct uncertain estimates and therefore to reduce the risks of assigning an incorrect amount of credits and debits in this complex sector.
\end{abstract}

Keywords: Forests, Land use, Mitigation, Accounting, Kyoto Protocol

\section{Setting the context}

As outlined in a previous commentary (Grassi et al. 2010) published in this journal, accounting rules for the land use, land use change and forestry (LULUCF) sector continue to be a very contentious argument in the negotiation forum. Under current rules, there is a high risk that a large portion of the overall credits issued to Annex I Parties - developed countries listed in Annex I of the UNFCCC - does not correspond to real emissions reductions and/or removals enhance-

Coalition for Rainforest Nations, 370 Lexington Avenue, 26th Floor, 10017 - New York, USA.

\section{@ Gea Galluzzi (geagalluzzi@yahoo.it)}

Received: Feb 24, 2010 - Accepted: Mar 19, 2010

Citation: Federici S, Galluzzi G, 2010. The treatment of land use, land use change and forestry in the post-2012 climate agreement: a perspective from non-Annex I Parties. iForest 3: 56-58 [online: 2010-05-17] URL: http://www.sisef.it/iforest/show.php? id $=533$ ments. The awarding of an undue (excessive) amount of credits weakens the environmental integrity of the Kyoto Protocol and its carbon market. In its recent communication on post-Copenhagen climate policy (European Commission 2010), the European Commission points out that for land use, land use change and forestry (LULUCF) current rules under the Kyoto Protocol, if continued, would entail lowering the actual stringency of the current emission reduction pledges and imply that reductions can be claimed without additional actions, which brings no real environmental benefit. Furthermore, some of the options currently under negotiation could weaken the real level of ambition of developed countries by up to $9 \%$ in relation to 1990 . Such weakening of targets is unacceptable for developing countries, especially since they are the ones suffering the most from the effects of climate change for which developed countries are largely responsible. This explains why the future treatment of Annex I Parties' accounting in LULUCF is such a crucial point in developing countries' agenda.

Aim of this paper is to outline the essential features of an accounting system for the LULUCF sector, which would be acceptable to non-Annex I Parties (developing countries).

To do so, it's useful to start with an analysis of the critical elements in current rules. These are related to the implementation of both the Kyoto Protocol's accounting principles and the UNFCCC's principles for GHG inventory reporting (UNFCCC 2006).

The Kyoto Protocol's accounting is based on the two main principles of additionality and of the basket approach.

The principle of additionality ensures credits be awarded only for those reductions in emissions and enhancements in removals which exceed an agreed threshold (which can be calculated through different methods such as a discounted base year level, a reference level, a business as usual level, etc).

Ensuring that mitigation actions are additional means making sure the Kyoto protocol awards only those efforts which produce positive socio-economic, policy and lifestyle changes with respect to the current situation, thus leading human society towards sustainability. If, on the contrary, additionality is not ensured - that's the case when business as usual removals and/or reductions in emissions are credited - then the change the Kyoto Protocol is supposed to fuel has no chance of being achieved.

The so-called basket approach ensures that reductions in emissions and enhancements in removals from different sectors such as energy, industrial processes, waste, etc. are equivalent in their contribution towards meeting a Party's commitment to lower its net emissions (net emissions are the aggregate of anthropogenic GHG emissions by sources and removals by sinks). Parties can thus concentrate their mitigation efforts in whichever sectors have lower marginal costs, enhancing the efficiency of the entire mechanism.

According to the UNFCCC's reporting principles (UNFCCC 2006), a Party shall produce time-series of estimates of its emissions and removals which allow to: clearly assess data, assumptions and methodologies applied for providing the estimate and repli-

Abbreviation list
- BAU: Business As Usual
- $\mathrm{CDM}:$ Clean Development Mechanism
- $\mathrm{CO}_{2}$ : Carbon Dioxide
- GHG: Greenhouse Gases
- IPCC: Intergovernmental Panel on Cli-
mate Change
- KP: Kyoto Protocol
- LULUCF: Land Use Land Use Change
and Forestry
- UNFCCC: United Nations Framework
Convention on Climate Change


cate it (transparency); demonstrate that changes in the estimated values along a timeseries are due to real changes in GHG emis sions/removals and not to differences in the data, assumptions and methodologies applied along the time-series (consistency); compare estimates of emissions and removals from different categories and reported by different Parties (comparability); have a complete time-series of all anthropogenic emissions by sources and removals by sinks (completeness); single out, for each estimate, the un biased mean and its uncertainty (accuracy).

Respect of these overarching principles guarantees the environmental integrity of the Kyoto Protocol, making it an effective mitigation instrument to fulfil the ultimate objective of the convention.

\section{Critical elements in the current accounting system of the LULUCF sector}

Current rules fail, in many respects, to put the above-mentioned principles into practice, therefore impairing the effectiveness of the Kyoto protocol.

Indeed, Parties included in Annex B:

- are required to report only anthropogenic fluxes of GHG from afforested/reforested and deforested areas under Article 3.3. When reporting under Article 3.4, Parties are allowed to "cherry pick" areas and activities within their national boundaries thereby they are free not to report on land areas that are sources of emissions and report on areas where removals can be achieved, all the while propelling the leakage of emissions from reported areas to excluded areas (violation of completeness);

- along the time-series may report increasing areas under each LULUCF activity, thus causing reported trends in GHG net emis sions to have no correspondence with real trends (violation of consistency);

- may select different definitions for a reported activity (e.g. forest management) and/or account for different activities, making reports non comparable among countries (violation of comparability);

- may account for quantities which are inferior to reported net emissions since some emissions can be cancelled by special provisions. Furthermore, bioenergy is accounted for with zero $\mathrm{CO}_{2}$ emissions, so that Parties formally reduce their emissions in the energy sector by increasing the production of bioenergy but are allowed not to account for the parallel depletion of carbon stocks in forest lands by simply excluding these from the accounting. In so doing, the net emissions reduction is fictitious, whereas the real balance of greenhouse gases consists in a surplus of emissions due to carbon stock decrease in lands excluded from the accounting; (violation of accuracy);

- account for all net emissions which occurred during the commitment period under Afforestation/Reforestation, Deforestation and Forest Management activities without subtracting the level of net emissions of a BAU scenario (e.g., the reference level - violation of additionality).

The consequence of all above violations is the input of credits on the carbon market which do not correspond to real reductions in emissions and/or enhancements in removals achieved over a reference/BAU level. Because of this so-called "hot air", the LULUCF sector was excluded from Annex A of the Kyoto Protocol and is therefore not fully included in the basket approach (together with the other sectors currently used for contributing to emissions reduction goals).

Other widely debated critical elements for a full accounting of the entire LULUCF sector under the Kyoto Protocol are quality and availability of LULUCF data. A fair solution is to adopt an accounting approach based on the principle of conservativeness (Grassi et al. 2008): by which potential overestimation of net emissions reductions and underestimation of net emissions increases are lowered to an agreed acceptable level. Conservativeness allows Parties to fill their data gaps and to reduce both the probability and the magnitude of any overestimation of the reductions / underestimation of the increases in net emissions when accounting, so allowing to deal with poor quality or missing data without mining the credibility of issued carbon credits.

\section{Outlining an acceptable accounting system for the \\ LULUCF sector}

Under current negotiations, there are three main lines of thought on LULUCF accounting

One of these considers the LULUCF as a sector which may deliver important opportunities for implementing mitigation actions; according to this view, the numerous and extensive deviations of current rules from the Kyoto Protocol's and UNFCCC's principles make the present system almost ineffective.

According to another, the LULUCF sector should ensure a certain degree of flexibility in order to help countries to meet their commitments; current rules already serve this purpose quite well, even if options for additional loopholes have been inserted in the current negotiation text.

The third line of thought perceives LULUCF as an impediment to the use of mitigation actions for achieving energy security through the complete substitution of fossil fuel; to this end, the inclusion of non-energy net emissions in the carbon market should be as restricted as possible and accepted only to the extent to which is serves to close the overall agreement.

Developing countries are more vulnerable to the impacts of climate change than developed countries, mostly because of lower technical and financial capabilities (UNFCCC 2007). Small island States in particular, according to IPCC scenarios, are likely to sink into the ocean before the end of this century. In this context, developing countries' paramount interest is to establish effective mitigation policies in order to reduce the negative effects of climate change as far as possible. It is clear that for these countries the first of the above mentioned arguments is predominant.

Therefore, an acceptable accounting system for the LULUCF sector is one which:

- ensures hot air is not accounted for (and therefore remunerates only effective additional mitigation actions);

- is capable of dealing with national circumstances and natural disturbances.

Among its options, the current text under negotiation (UNFCCC 2009) contains the necessary elements for reaching those goals, by:

- outlining a complete accounting system of all anthropogenic emissions by sources and removals by sinks occurring on managed lands within the country's boundary;

- including provisions for a reference level. This discounts net emissions occurring under a BAU scenario from crediting and debiting and removes the risk of accounting "hot air". In the calculation of the reference level, different national circumstances as age legacy, energy mix, etc. can be accommodated;

- defining provisions to carry over unexpected peaks in emissions due to extreme natural disturbances to subsequent commitment periods, so that Parties are allowed to offset these emissions by accounting for the gradual regeneration of vegetation which usually follows disturbances. This removes the negative effects that sudden natural disturbances would have on compliance if the affected Party were called to account for the resulting emissions all together at one time; at the same time it sets a fair accounting system which does not cancel such emissions entirely, with the excuse of their unpredictability and nonanthropogenic nature. In practice, the carry over is equivalent to spreading net emissions from natural disturbances over a longer period (the return period) than the commitment period. It serves to mitigate the temporary imbalance in the annual GHG inventory which derives from the typical "slow-in and fast-out" pattern of the carbon cycle in biological systems.

\section{Why use a reference level and how to calculate it}

As mentioned above, in order to ensure en- 
vironmental integrity, BAU net emissions those which would occur if no mitigation action was implemented - should not be credited. These include net emissions from natural disturbances (with the exclusion of unpredictable extreme events) and those which are not a direct result of human actions, such as those deriving from nitrogen deposition and $\mathrm{CO}_{2}$ fertilization. The use of a reference value (the reference level) against which net emissions in the commitment period are accounted solves this problem. It allows measuring changes in net emissions compared to a net emissions scenario which would normally occur unless a Party undertook active efforts to improve it.

Since the reference level would be defined at the national level, country-specific circumstances - such as age-class legacy, current and past management practices, etc. can be kept into account, thus not resulting in penalizations for any Party. For instance, in a country with old forests behaving as naturally declining sinks, using historical net emissions data as a reference level in accounting would result in debits arising during the commitment period. On the contrary, by defining and using a national BAU scenario, the Party would not incur in debits for its old forests, unless of course it actively increased harvesting, since the natural ageing and decline of the forest would be included in the projection.

The current negotiation text includes suggestions on how to establish and calculate the reference level. The best among the options would be to use a reference period instead of a reference year, to reduce the impact of inter-annual variability on the estimations. Furthermore, in order to fully factor out BAU net emissions which would otherwise be accounted for and produce "fictitious" credits, the reference period shall coincide with the commitment period.

During this period, net emissions for the reference level could be calculated as:

- an aspirational goal, similar to the assigned amount (calculated by discounting historical net emissions by a factor which represents a Party's commitment to mitigation);

- a BAU scenario similar to the baseline concept used in CDM projects, which defines the expected trend in net emissions if no mitigation efforts were undertaken;

- a mixture of both approaches.

An important issue when defining the national reference level for the LULUCF sector is the extent to which a forecast increase in harvesting (in most cases due to an increase in bioenergy production) should be included. The inclusion of these forecast carbon stock losses in the reference level makes them debit free, since the reference level corresponds to the amount of allowed net emissions. Furthermore, if this inclusion makes the reference level positive - turning the forest from a net sink into a net source and thus representing a degradation - the emissions between zero and the forecast positive value will not only be debit free, but will even give right to credits provided that emissions during the commitment period stay below the forecast limit.

Considering that the Kyoto Protocol is an instrument meant to award sustainable development and that a net decrease of carbon stocks over a long period - 8 years is the expected duration of the next commitment period - invariably corresponds to a degradation of forests, a clause that avoids the reference level being higher than zero is clearly needed. If this is prevented, the reference level will allow Parties to receive incentives for keeping forests functioning as sinks and will penalize them as soon as the management practices they choose to implement transform forests into a source.

\section{Concluding remarks}

In the course of this year, we hope the in- ternational negotiations on a post- $2012 \mathrm{com}$ prehensive instrument for dealing with climate change will make progress towards an agreement in the next Climate Conference in Mexico. We firmly believe that a transparent and effective accounting system which closely mirrors the principles contained in the Kyoto protocol and the UNFCCC and is capable of propelling mitigation actions in the LULUCF sector, should be a core element of such an accord.

\section{References}

European Commission (2010). International climate policy post-Copenhagen: acting now to reinvigorate global action on climate change. EC Communication (policy paper) 86, March 2010. [online] URL: http://ec.europa.eu/environment/ climat/pdf/com_2010_86.pdf

Grassi G, Federici S, Pilli R (2010). What happened to forests in Copenhagen? iForest 3: 30-32. [online] URL: http://www.sisef.it/iforest/ show.php?id=529

Grassi G, Monni S, Federici S, Achard F, Mollicone D (2008). Applying the conservativeness principle to REDD to deal with the uncertainties of the estimates. Environmental Research Letters 3: 035005. - doi: 10.1088/1748-9326/3/3/035005

UNFCCC (2006). Updated UNFCCC reporting guidelines on annual inventories following incorporation of the provisions of decision 14/CP11. [online] URL: http://unfecc.int/resource/docs/ 2006/sbsta/eng/09.pdf

UNFCCC (2007). Climate change: impacts, vulnerabilities and adaptation in developing countries. [online] URL: http://unfccc.int/resource/ docs/publications/impacts.pdf

UNFCCC (2009). Report of the ad hoc working group on further commitments for Annex I Parties under the Kyoto Protocol on 10th session. Copenhagen (Denmark) 7-15 December 2009, Agenda Item 5. [online] URL: http://unfccc.int/ resource/docs/2009/awg10/eng/17.pdf 